\title{
AN ANALYSIS OF THE ACCOUNTING PRACTICES OF JUNIOR EXPLORATION COMPANIES IN SOUTH AFRICA
}

\author{
Joline Sturdy* \\ University of South Africa \\ sturdj@unisa.ac.za.
}

Received: April 2013

\author{
Christo Cronjé+ \\ University of South Africa \\ cronjcj@unisa.ac.za
}

Accepted: May 2014

\begin{abstract}
IFRS 6, Exploration for and evaluation of mineral resources, allows junior exploration companies to develop their own accounting policies with regard to exploration and evaluation expenditure. This will result, as indicated by the research problem, in inconsistent accounting practices among different companies. The objective of this article is to identify the various accounting treatments of exploration expenditure and to develop recommendations for consistent application of accounting practices. Relevant literature is critically analysed and the judgement sampling method is used to select junior exploration companies to participate in a self-administered survey to identify the various accounting treatments of exploration and evaluation expenditure by junior exploration companies. The findings of this study show that, despite the time and resources expended by the International Accounting Standards Board (IASB) in the extractive activities project, nothing has changed in the last 40 years. Progress in the standardisation of accounting for exploration and evaluation expenditure can be made if the exemptions included in IFRS 6 are removed or only the successful-efforts method incorporated into IFRS 6.
\end{abstract}

Keywords

Junior exploration companies; pre-exploration expenditure; exploration expenditure; exploration and evaluation assets; accounting policies; accounting practices; IFRS 6

\#Ms J Sturdy is a senior lecturer in the Department of Financial Governance, University of South Africa, South Africa. +Prof CJ Cronjé is a professor in the Department of Financial Governance, University of South Africa, South Africa. 


\section{INTRODUCTION}

The accounting methods for the extractive industry have been debated over the last 40 years (Cortese \& Irvine, 2010; Bryant, 2003). With widespread use of International Financial Reporting Standard (IFRS), the International Accounting Standards Board (IASB) recognised that extractive activities was an area in which there was little guidance and extractive activities were scoped out of most of the relevant standards (KPMG, 2009). IFRS 6, Exploration for and Evaluation of Mineral Resources, addresses the accounting for exploration and evaluation expenditures. It was developed as an interim standard to allow entities adopting IFRSs to continue to apply their existing accounting policies for these expenditures (IFRS Foundation, 2010). In other words, IFRS 6 failed to eliminate choice and codified existing accounting practice for extractive industries entities (Cortese \& Irvine, 2010).

With the promulgation of the Mineral and Petroleum Resources Development Act 28 of 2002 (MPRDA) the mineral rights policy of South Africa changed from a dual private- and stateowned mineral rights policy to a state-owned mineral policy. The objectives of the MPRDA are to give the state the right to exercise sovereignty over and custodianship of the nation's mineral and petroleum resources (Republic of South Africa, 2002). One of the consequences of this change was that this allowed a significant number of junior exploration companies to become active in the extractive industry of South Africa. There are various phases of mining, but junior exploration companies are involved only in the pre-exploration and exploration phase.

IFRS 6 is applicable to exploration and evaluation expenditure incurred during the exploration phase. During the pre-exploration phase junior exploration companies will apply the definitions of assets and expenses from the Conceptual Framework, and the principles of asset recognition in IAS 16, Property, plant and equipment, and IAS 38, Intangible assets (IASB, 2013).

This article should be of interest to academics, investors, junior exploration companies and standard setters. The results of this article again highlight that little progress has been made in the last 40 years with regard to the consistent, acceptable accounting treatment of exploration and evaluation expenditure.

The rest of this article is organised as follows: firstly, the research problem and objective of the article is stated, and thereafter the selected methodology is discussed. In the section that follows the literature review is provided, and this is followed by the empirical results. Finally the conclusion and recommendations are presented.

\section{RESEARCH PROBLEM AND OBJECTIVE}

The research problem of this article is formulated as follows: IFRS 6 allows entities to develop their own accounting policies with regard to exploration and evaluation expenditure, an arrangement that will result in inconsistent accounting among different companies.

The objective of this article is to identify the various accounting treatments of exploration expenditure by junior exploration companies and to develop recommendations for the consistent application of accounting practices in respect of junior exploration companies. 


\section{METHODOLOGY}

The research is based on a qualitative analysis of current literature and a self-administered survey.

The qualitative analysis of current literature includes a detailed analysis of the International Financial Reporting Standards issued by the IASB and analysis of other sources of current literature, such as books, articles, periodicals and other studies.

The empirical research involves a self-administered survey with a web-based survey being used to collect the data from junior exploration companies. LimeSurvey was the survey tool that was used. Purposive, non-probability sampling was used in selecting the sample of junior exploration companies. In non-probability sampling there is no guarantee that each element in the population will be represented in the sample (Leedy, 1988:152). In this article the judgement sampling method is used. This method is used to ensure that the respondents in the study have the necessary common experience that will result in useful research data (Kolb, 2008:112).

\section{LITERATURE REVIEW}

\subsection{Exploration and evaluation assets of junior exploration companies}

There is a sequence of activities undertaken by junior exploration companies. These activities initially comprise the legal rights to explore an area with exploration activities, which then leads to knowledge and, ultimately, mineral reserves being identified (IASB, 2010). FIGURE I illustrates the relationship between the exploration results, mineral resources and mineral reserves.

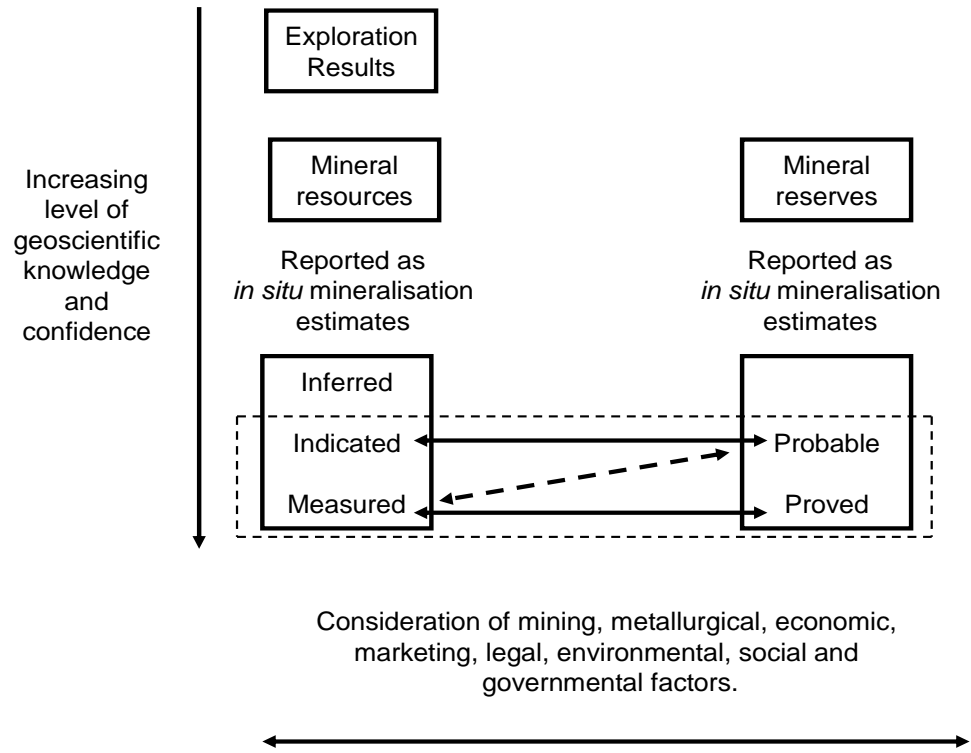

FIGURE 1: Relationship between exploration results, mineral resources and mineral reserves Source: $\quad$ SAMCODE, 2007 
The South African Code for the Reporting of Mineral Asset Valuation (SAMVAL) (SAMCODE, 2008) refers to an 'inferred mineral resource' as the lowest level of confidence, while 'measured mineral resources' indicates the highest level of confidence. A 'mineral reserve' refers to the economically mineable material in a mineral resource. When a mineral reserve is classified as a proven mineral reserve such a mineral reserve represents the highest level of confidence obtainable.

The main assets of junior exploration companies are firstly the rights to explore an area, secondly the knowledge gained from exploration work done in the area and lastly the mineral reserves identified by the exploration work performed. The results obtained from the exploration phase will indicate whether the mineral resources are inferred, indicated or measured. From these results a company will be able to classify the mineral reserves as either probable or proven.

\subsection{Phases of mining applicable to junior exploration companies}

There are various phases of mining, but junior exploration companies are involved in only the pre-exploration and exploration phase. FIGURE 2 illustrates the different phases of mining.

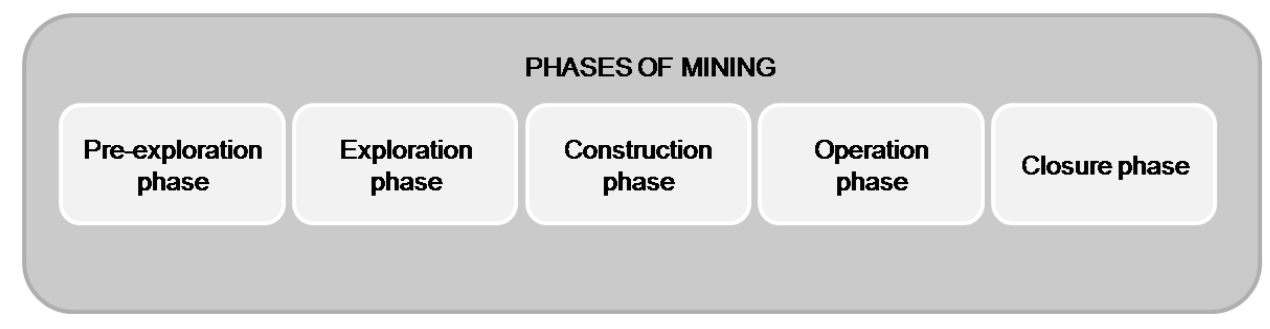

\section{FIGURE 2: Phases of mining}

Source: Own observation

The pre-exploration phase refers to all expenditure incurred before an entity has obtained the legal right to explore a specific area - hence all expenditure incurred by junior exploration companies before a prospecting right is obtained. The exploration phase begins when the prospecting right is obtained and ends upon completion of a feasibility study (KPMG, 2009). The mine construction phase generally begins after completion of a feasibility study and ends upon the commencement of production (operation phase) (KPMG, 2009). The closure phase commences with the termination of production and includes activities such as decommissioning and dismantling equipment, and restoring the mine site.

IFRS 6 is applicable only to exploration and evaluation expenditure incurred after the entity obtains a legal right to explore a given area; therefore junior exploration companies will apply the definitions of assets and expenses from the Conceptual Framework, and the principles of asset recognition in IAS 16, Property, plant and equipment, and IAS 38, Intangible assets, during the pre-exploration phase (Cengage Learning, 2011) (KPMG, 2005). 


\subsection{Pre-exploration expenditure}

The treatment of pre-exploration expenses is obtained from the Conceptual Framework (IASB, 2013) definitions of assets and expenses, and by applying the principles of asset recognition as contained in IAS 16 and IAS 38 (IASB, 2013).

\subsubsection{The Conceptual Framework}

The Conceptual Framework defines an asset as a resource which is controlled by an entity as a result of past events and from which future economic benefits are expected to flow to the entity in question (IASB, 2013). In the case of junior exploration companies, 'control' exists where the entity has a legal right to explore the specified area and exploit any mineral deposits within it (PWC, 2007). The cost of any asset can be measured reliably using the actual expenditure incurred. However, not all pre-exploration meets the requirement that future economic benefits must be probable (PWC, 2007). In these circumstances 'future economic benefits' refers to the potential to contribute to the cash flow of the entity (Venter, 2003:2). Even if an asset meets the definition of an element in the financial statements, the Conceptual Framework stipulates that such an asset may be recognised only if it is probable that future benefits will flow to the entity from that asset and if the asset has a cost or value that may be measured reliably (IASB, 2013). The expectation that future economic benefits will flow to the entity must be sufficiently certain so as to be regarded as probable (Venter, 2003:2). Generally, pre-exploration expenditure cannot be associated with any specific mineral reserves, as they generally are speculative in nature (KPMG, 2005). Although it may be possible to measure the cost of this expenditure reliably, the probability of future economic benefits may not be sufficiently certain at the stage at which the expenditure was incurred and, thus, it is highly likely that the expenditure may be recognised as an expense.

\subsubsection{IAS 16 Property, plant and equipment}

Although the scope of IAS 16 excludes the recognition and measurement of exploration and evaluation assets, it does, nevertheless, apply to the property, plant and equipment that are used to develop these assets (IASB, 2010). Any items of plant and equipment used during the pre-exploration phase are capitalised within property, plant and equipment and depreciated over their useful lives (PWC, 2007).

\subsubsection{IAS 38 Intangible assets}

Typical pre-exploration expenditure includes the acquisition of speculative seismic data and expenditure on the subsequent geological and geophysical analysis of this data (KPMG, 2005). These costs might qualify for recognition as an intangible asset to the extent that preexploration costs give rise to proprietary information that the entity has the ability to control (KPMG, 2005). A number of pre-exploration expenditures may include pre-acquisition expenditure relating to the acquisition of an intangible asset, for example expenditure directly attributable to the acquisition or application of a prospecting right. This expenditure will be recognised as part of an intangible asset, for example prospecting rights, in accordance with IAS 38 (IASB, 2013) (IASB, 2010). 


\subsection{Exploration expenditure}

As soon as a company possesses some form of legal right over exploration, for example its application for a prospecting right was approved, the exploration and evaluation phase, in accordance with IFRS 6 (IASB, 2013), commences.

\subsubsection{Developing an accounting policy}

IFRS 6 permits junior exploration companies to determine their own accounting method for exploration expenditure. In deciding an accounting policy for exploration and evaluation expenditure the main issue is to determine whether to capitalise these costs or to record them as expenses in the period in which they were incurred. The alternative methods of accounting for exploration and evaluation expenditure are discussed below:

\section{(a) Full-expense method}

The full-expense method is the most conservative method (Cartwright, 1991) and involves expensing all exploration costs as they are incurred. Exploration activities usually take place over a considerable period of time and with this method it may be difficult to evaluate a company's efficiency as an operator in the mineral industry (Cartwright, 1991). Cartwright (1991) is of the opinion that this method serves better to mask the true cost of finding an asset rather than serving to prevent the overvaluation of the asset.

\section{(b) Full-cost method}

The idea of the full-cost method was introduced in the late 1950s (Malmquist, 1989; Lilien \& Pastena, 1982). The full-cost method represents another extreme treatment of exploration costs (Gerhardy, 1999). The full-cost method is one of the two most popular methods in accounting for exploration and evaluation expenditure, the other method being the successfulefforts method (Bryant, 2003; Epstein \& Jermakowicz, 2009). In terms of the full-cost method all exploration costs, successful or not, are capitalised until an ore reserve is eventually found and then amortised over the discovered reserve on a pro rata basis (Malmquist, 1989). This method does not use a separate cost centre based on a particular mineral resource, but uses a larger geographical area (such as a whole country) as its cost centre (PWC, 1999:11). The full-cost method yields a higher book asset value than the successful-efforts method (Malmquist, 1989). In periods of large write-offs this method significantly distorts the net income, while in periods in which more than one viable ore deposit is found the problem of correctly allocating these capitalised exploration expenses arises (Cartwright, 1991). This method is commonly used among junior exploration companies with no producing assets where exploration and evaluation activities are in progress and for which an outcome has not yet been determined (PWC, 2007). The full-cost method is considered to be the most liberal of all methods.

\section{(c) Successful-efforts method}

The successful-efforts method is one of the two most popular methods in accounting for exploration and evaluation expenditure (Bryant, 2003; Epstein \& Jermakowicz, 2009). The successful-efforts method capitalises successful exploration expenses that can be related directly to an ore reserve and unsuccessful expenses are expensed. (Bryant, 2003) (Malmquist, 1989). 
A problem with this method, however, is that until an ore reserve has been defined, the entity will not know which costs to capitalise (Cartwright, 1991). On the other hand, one of the main benefits of this method is that the users of financial statements are able to assess management in terms of its unsuccessful exploration activities (Venter, 2003:3). In view of the lack of accounting for the failed projects that were explored before a successful project was discovered this method actually conceals the actual cost of the asset(s) (Cartwright, 1991). The largest entities use almost exclusively the successful-efforts method, as they are able to absorb the cost of unsuccessful exploration efforts (Malmquist, 1989) (Cortese \& Irvine, 2010).

\section{(d) Area-of-interest method}

The area-of-interest method identifies a geological area that potentially contains ore reserves, and capitalises all costs incurred in identifying or proving the area of interest (PWC, 1999:10). In terms of this method costs are capitalised until the project is proven successful (thus become viable to mine) or otherwise (Gerhardy, 1999). The area-of-interest method represents another major approach to the capitalisation of exploration and evaluation expenditure and is fairly commonly used in the mining industry (Epstein \& Jermakowicz, 2009; Cortese, Irvine \& Kaidonis, 2009).

\section{(e) Expense-and-reinstate method}

The expense-and-reinstate method records all exploration costs as expenses as they are incurred and, as soon as a viable ore reserve has been detected, the previously related expensed exploration costs will be reinstated as an asset (Gerhardy, 1999). An entity needs adequate internal accounting controls to record separate project expenses in order to ensure that the correct expensed amounts only are reinstated.

\section{(f) Area-of-interest-with-provision method}

The area-of-interest-with-provision method capitalises all exploration costs associated with an area and, at the same time, a provision of an equal amount is created against the area by means of a charge to the profit and loss account (Gerhardy, 1999). This full provision remains in place until the economic viability of the area has been established (Gerhardy, 1999). The provision is reversed via the profit and loss account as soon as the economic viability of the area has been established. The net effect of this method and the expense and reinstate method on the financial statements of an entity will be the same.

\subsubsection{Classification}

IFRS 6 (IASB, 2013) requires exploration and evaluation assets to be classified as either tangible or intangible assets according to the nature of the assets acquired. The classification of such assets in this manner affects the subsequent accounting of the assets (Chung \& Narasimhan, 2006:287). Current industry practice for the classification of exploration and evaluation assets varies (KPMG, 2005). Some entities take the view that exploration and evaluation assets form part of property, plant and equipment because the underlying asset is a tangible asset (i.e., the mineral reserve) (PWC, 2007). Others have concluded that any assets in respect of exploration and evaluation expenditure must be attributed to the relevant prospecting right and recognised as an intangible asset (PWC, 2007). 


\subsubsection{Measurement}

At initial recognition, exploration and evaluation assets are measured at cost. The measurement after recognition guidelines contained in either IAS 16 or IAS 38 (IASB, 2013) will be used depending on the classification of the asset. In terms of IFRS 6 (IASB, 2013), subsequent to initial recognition an entity should choose either the cost or the revaluation model to be applied to the exploration and evaluation assets.

The cost model refers to the historical costs incurred at initial recognition. Costs of either tangible or intangible assets are depreciated or amortised over the estimated useful life of the assets concerned (Chung \& Narasimhan, 2006:288). The current practice is to depreciate the prospecting rights component of an exploration and evaluation assets over the term of the prospecting right (IASB, 2010). According to the MPRDA, a prospecting right in South Africa may not exceed five years and it may be renewed once for a period not exceeding three years (Republic of South Africa, 2002). The cost model is commonly used by entities in the extractive industries to measure minerals properties (IASB, 2010).

Tangible exploration and evaluation assets that are carried at the revaluation model refer to their fair value. The fair value is calculated by using valuation techniques discussed in IFRS13, Fair value measurement (IASB, 2013). According to IFRS 13, there are three widely used valuation techniques, namely the market approach, cost approach and income approach (IASB, 2013). Generally, tangible exploration and evaluation assets are specialised and rarely sold, and it may be difficult to find an observable market that may serve as a basis for estimating market value (KPMG, 2005). As the income that may be produced in the future by an exploration and evaluation asset are highly uncertain, it is unlikely that an income approach will give a reliable estimate of fair value of a tangible exploration and evaluation asset (KPMG, 2005). Due to the difficulties in determining the fair value for tangible exploration and evaluation assets, it is anticipated that the revaluation of these assets will be rare (KMPG, 2005) (IASB, 2010). The revaluation model in IAS 38 (IASB, 2013) may be used only if it is possible to establish the asset's fair value by reference to an active market. An active market exists if the traded items are homogeneous; there are normally willing buyers and sellers available and prices are made available publicly (Chung \& Narasimhan, 2006:289). It will be very rare for an intangible exploration and evaluation asset to meet the abovementioned criteria due to the nature of the asset (KPMG, 2005) (IASB, 2010).

\subsubsection{Impairment}

IFRS 6 specifies the identification and level of impairment of exploration and evaluation assets, although the impairment is measured in accordance with IAS 36 once the impairment has been identified (Nichols, 2005:270). IFRS 6 (IASB, 2013) stipulates that exploration and evaluation assets are tested for impairment if the possibility exists that the carrying amount of these assets may not be recoverable. In order to identify an exploration and evaluation asset that may be impaired IFRS 6 identifies a non-exhaustive list of facts and circumstances that might indicate the need for an impairment test (IASB, 2013). It is, however, not necessary that exploration and evaluation assets be tested for impairment until such time that sufficient data is available to determine the technical feasibility and commercial viability of these assets (IASB, 2010).

As exploration and evaluation assets do not generate cash inflows they are tested for impairment as part of a group of assets. IFRS 6 (IASB, 2013) specifies that an entity should 
develop a policy of allocating these assets to groups of cash-generating units (CGUs) and apply the policy consistently. The limitation as specified in IFRS 6 is that the CGU to which the assets are allocated should not be larger than a segment of the entity as specified by IFRS 8 (IASB, 2013). IFRS 6 allows some flexibility when defining a CGU; this may mean that each area of interest, contiguous ore body or extraction unit (such as an oil rig) may be treated as a CGU. The identification of CGUs requires judgement and may be one of the most difficult areas of impairment testing for exploration and evaluation assets (KPMG, 2005) (IASB, 2010).

\subsubsection{Disclosure}

IFRS 6 (IASB, 2013) requires an entity to disclose its accounting policies for exploration and evaluation expenditure, including the recognition of exploration and evaluation assets. It shall also disclose the amounts of assets, liabilities, income and expenses, and operating and investing cash flows arising from the exploration and evaluation of mineral resources. Exploration and evaluation assets shall be treated as a separate class of assets. IFRS 6 does not require any disclosure relating to the mineral resources or reserves of junior exploration companies.

The literature review reveals that because IFRS 6 allows entities to develop accounting policies for the recognition of exploration and evaluation expenditure without considering the Conceptual Framework (IASB, 2013) and other IFRSs it will result in inconsistent accounting practices among junior exploration companies.

\section{EMPIRICAL RESULTS}

This section focuses on a survey of junior exploration companies that highlights the inconsistent accounting treatment of pre-exploration and exploration expenditure by junior exploration companies.

\subsection{The population}

Junior exploration companies are companies that are involved exclusively in basic prospecting and exploration activities and that do not perform mining activities. Junior exploration companies will therefore only be in possession of prospecting rights. A prospecting rights list and a separate mining rights list were obtained from the Mineral Regulation branch of the Department of Mineral Resources (DMR) in September 2009 with contact details of the holders of the rights. There were 4267 prospecting rights and 396 mining rights in issue during September 2009. Excluding the holders of prospecting rights as well as mining rights were 3625 prospecting rights in issue at that time. TABLE 1 depicts the ownership categories of the 3625 prospecting rights.

The target population should comprise everyone of interest who could possibly be included in a research study and to whom the research findings may reasonably be generalised (Czaja \& Blair, 2005:130). This article focuses on the accounting practices of junior exploration companies and, thus, the prospecting rights held by $\mathrm{CCs}$, individuals and others were not included in the article. The target population thus comprises private companies and public companies as the holders of the prospecting rights. 


\section{TABLE 1: Holders of prospecting rights only}

\begin{tabular}{lc}
\hline Holder of prospecting rights & Number of rights \\
\hline Private companies ((Pty) Ltd) & 2428 \\
Close corporations (CC) & 482 \\
Individuals & 390 \\
Public companies (Ltd) & 228 \\
Other & 97 \\
TOTAL & 3625 \\
\hline
\end{tabular}

Source: Authors' analysis

\subsection{The sample}

Junior exploration companies in possession of more than five prospecting rights and with a company registration date after the year 2003 were selected to participate in the survey. The probability is higher that companies with a greater number of prospecting rights would have actively exploited one or more of the areas they have a prospecting right over, and this article focuses on junior exploration companies that had entered the extractive industry in South Africa as a result of the change in the mineral policy of South Africa in 2004. TABLE 2 provides a breakdown of companies with more than five prospecting rights by their registration dates.

\section{Table 2: Breakdown of company registration dates with more than five prospecting rights}

\begin{tabular}{lcc}
\multicolumn{1}{c}{ Company registration date } & No. of & No. of \\
& Public companies & Private companies \\
\hline Before the year 2000 & 7 & 7 \\
Between years 2000 and 2003 & 2 & 15 \\
After the year 2003 & 2 & 56 \\
TOTAL & 11 & 78 \\
\hline
\end{tabular}

Source: Authors' analysis

TABLE 2 clearly shows that with the change in the mineral policy of South Africa during 2004, the opportunities for new role players in the extractive industry increased significantly. The two public companies and the 56 private companies were selected to participate in the survey. This total of 58 companies selected for the sample held a total of 542 prospecting rights among them.

Of the 58 companies, five participants could not be contacted due to contact numbers that no longer exist or were wrong, four emails bounced back and 15 companies indicated they were unable to respond for various reasons. This left 34 expected responses. Eleven junior exploration companies participated in the survey. Five of the 11 responses represent a group of companies that have the same management. 


\subsection{The questionnaire}

The self-administered survey consisted of a web-based questionnaire. Interaction with survey respondents may be divided into three main components: contact, response and follow-up (Schonlau, Fricker \& Elliot, 2002). The selected junior exploration companies were contacted telephonically during July 2010 and the email addresses of those persons in management accountable for the companies' compliance with IFRS were obtained. The invitation to participate in the survey was included in an email invitation, and two follow-up reminders were emailed to the selected respondents.

The questionnaire was compiled on the basis of the literature review. The questionnaire was mainly a structured questionnaire that specified alternatives for the respondents. As such the questionnaire consisted of dichotomous choice and multiple-choice questions. A dichotomous choice question allows the participant to choose one of two responses that are usually opposite to each other. An example is a question where the participant would tick either yes or no (Kolb, 2008:202). Multiple-choice questions are used when the researcher has a number of variables that may affect the choice of the participant (Kolb, 2008:202). The multiple-choice questions in this questionnaire allowed the participant to determine one answer only that best described or was true.

The questionnaire had the following four focus areas:

(1) To determine the treatment of pre-exploration expenditure, in order to establish whether the accounting treatment of pre-exploration expenditure by junior exploration companies is consistently applied.

(2) To determine the treatment of exploration expenditure by establishing the accounting policies, classification of exploration and evaluation assets, and subsequent measurement model used by junior exploration companies to account for exploration and evaluation assets, in order to verify that various policies are used to account for exploration expenditure by junior exploration companies.

(3) To determine whether junior exploration companies test for impairment of their exploration and evaluation assets and the frequency of the impairment testing, in order to verify that junior exploration companies do test for impairment as per the requirements of IFRS 6 .

(4) To establish if junior exploration companies disclose information relating to their mineral resources and reserves, in order to determine if junior exploration companies disclosure information relating to their mineral assets even if it is not required by IFRS 6 .

\subsection{Results and discussion of survey}

The results are given as a proportion of the total of 11 respondents.

\subsubsection{Treatment of pre-exploration expenditure}

The treatment of pre-exploration expenses may be obtained from the Conceptual Framework definitions of assets and expenses, and by applying the principles of asset recognition as contained in IAS 16 and IAS 38. TABLE 3 shows the treatment of certain pre-exploration-related expenditure for accounting purposes as either an asset or expense by the respondents. The 
results in TABLE 3 confirm that the accounting treatments of pre-exploration expenditure by junior exploration companies are not consistently applied.

TABLE 3: Treatment of pre-exploration expenditure

\begin{tabular}{|c|c|c|c|c|}
\hline Pre-exploration expense & Asset & Expense & $N / A$ & Total \\
\hline Acquisition of third-party studies over regions of land & 10 & 1 & 0 & 11 \\
\hline $\begin{array}{l}\text { Acquisition of studies to determine the exploration } \\
\text { history of an area }\end{array}$ & 10 & 1 & 0 & 11 \\
\hline Preparatory work to prepare exploration team & 2 & 9 & 0 & 11 \\
\hline Developing geological hypotheses & 7 & 4 & 0 & 11 \\
\hline Application for prospecting rights & 0 & 11 & 0 & 11 \\
\hline Equipment and infrastructure & 10 & 0 & 1 & 11 \\
\hline $\begin{array}{l}\text { General overhead costs directly attributable to pre- } \\
\text { exploration activities }\end{array}$ & 0 & 11 & 0 & 11 \\
\hline
\end{tabular}

Source: Authors' analysis

\subsubsection{Treatment of exploration expenditure}

IFRS 6 allows entities to develop their own accounting policies with regard to exploration and evaluation expenditure incurred. Two of the respondents use the full-expense method, seven use the full-cost method, and the remaining two use the area-of-interest-with-provision method. As mentioned in section 4.4.1, the full-cost method is one of the two most popular methods in accounting for exploration and evaluation expenditure, and this was also the most popular method used by the respondents. The respondents confirm that there are various accounting practices used by junior exploration companies to account for exploration-related expenditure.

The classification of exploration and evaluation assets as tangible or intangible is applicable only to the nine respondents with accounting policies that aimed at capitalisation of exploration and evaluation costs. TABLE 4 show the classification of certain exploration and evaluation assets as tangible or intangible by the respondents.

TABLE 4: Classification as tangible or intangible

\begin{tabular}{|c|c|c|c|c|}
\hline Pre-exploration expense & Tangible & Intangible & $N / A$ & Total \\
\hline Acquisition rights to explore & 0 & 9 & 2 & 11 \\
\hline $\begin{array}{l}\text { Topographical, geological, geochemical or } \\
\text { geophysical studies }\end{array}$ & 0 & 9 & 2 & 11 \\
\hline Exploration drilling & 0 & 9 & 2 & 11 \\
\hline Trenching & 0 & 9 & 2 & 11 \\
\hline Sampling & 0 & 9 & 2 & 11 \\
\hline Technical feasibility studies & 0 & 9 & 2 & 11 \\
\hline
\end{tabular}




\begin{tabular}{lcccc}
\hline Pre-exploration expense & Tangible & Intangible & N/A & Total \\
\hline $\begin{array}{l}\text { Exploration staff-related costs } \\
\text { General overhead costs directly attributable to } \\
\text { exploration and evaluation activities }\end{array}$ & 0 & 9 & 2 & 11 \\
$\begin{array}{l}\text { Equipment and infrastructure } \\
\text { Equal }\end{array}$ & 9 & 0 & 2 & 11 \\
\hline
\end{tabular}

Source: Authors' analysis

The respondents to the survey concluded that exploration expenditure, except equipment and infrastructure, must be attributed to the relevant prospecting licence, and recognised the related expenditure as an intangible asset.

As mentioned in Section 4.4.3, the revaluation method is rarely used in the measurement of intangible exploration and evaluation assets, as it is difficult to comply with the conditions of an active market. Of the respondents, four use the cost model and five use the revaluation model as subsequent measurement of their exploration and evaluation asset, including intangible exploration and evaluation assets. Current practice is to depreciate the exploration and evaluation assets over the term of the prospecting right. Seven of the respondents use the prospecting rights period to determine the useful life of the exploration and evaluation asset, while two respondents instead determined that, if a mine were established, the exploration and evaluation assets were either amortised accordingly or when the prospecting rights had expired, or, when the project was no longer considered viable for any further prospecting, the exploration and evaluation assets were impaired. Two respondents use the full-expense method and will not have a subsequent measurement model for exploration and revaluation assets.

\subsubsection{Impairment testing}

IFRS 6 stipulates that the exploration and evaluation asset should be tested for impairment only when facts and circumstances indicate the need for an impairment test. All nine respondents with an exploration and evaluation asset tested the asset for impairment at each reporting period and also indicated that they have an accounting policy in place for allocating their exploration and evaluation assets to CGUs. The respondents tested the exploration and evaluation asset more frequently than required by IFRS 6 .

\subsubsection{Disclosure of mineral resources and reserves}

IFRS 6 does not require any disclosure relating to the mineral resources or reserves of junior exploration companies. Seven of the respondents indicated they do disclose some information relating to the mineral resources or reserves, while four respondents indicated they do not disclose any information.

The empirical results confirm there are various accounting treatments of exploration expenditure by junior exploration companies.

\subsection{Limitations of the empirical investigation}

Judgement sampling is a subdivision of purposive sampling, and thus it cannot be guaranteed that the sample is representative of the population of junior exploration companies. The total sample comprised 58 companies, although 34 responses were expected. Of the 34 expected 
responses only 11 companies responded, and five of the 11 responses represent a group of companies that have the same management. Due to the method of sampling and response rate the results of the empirical findings may not be generalised to all junior exploration companies.

\section{CONCLUSION AND RECOMMENDATIONS}

The research problem of this article arose from IFRS 6 allowing entities to develop their own accounting policies with regard to exploration and evaluation expenditure - an arrangement that will result in inconsistent accounting among different entities. The objective was to identify the various accounting treatments of exploration expenditure by junior exploration companies and to develop recommendations for consistent application of accounting practices in respect of junior exploration companies.

The literature review and empirical results reveal that the definitions of assets and expenses in the Conceptual Framework in the treatment of pre-exploration expenditure may lead to inconsistent treatment of pre-exploration expenditure by junior exploration companies. IFRS 6 allows junior exploration companies to develop their own accounting policies with regard to exploration and evaluation expenditure during the exploration phase, and the literature review and empirical results indeed confirmed that exploration expenditure is accounted for differently by junior exploration companies.

Despite the time and resources expended by the IASB in the extractive activities project nothing has changed in the last 40 years, and in December 2012 the IASB effectively discontinued the extractive activities project and activated a broader research project on intangible assets. It is clear that a comprehensive intangible asset standard dealing with the issues relating to the accounting of exploration expenditure by junior exploration companies will be available only in a number of years.

The difficulties and uncertainties associated with the accounting of exploration and evaluation expenditure has been known by the extractive industry and standard setters for a long time. The difficult question is when expenditure with uncertain future economic benefits is deemed an asset. Often there is a long lead-time between exploration, proving of mineral reserves and revenue (Luther, 1996). Progress can be made in the standardisation of accounting for exploration and evaluation expenditure while the research project on intangible assets is under way. Firstly, IFRS 6 should remove the exemption of paragraphs 11 and 12 of IAS 8, Accounting policies, changes in accounting estimates and errors, as this will ensure the accounting policies will have to consider the Conceptual Framework (IASB, 2013) and other IFRSs or should incorporate only the successful-efforts method supported by the majority (78\%) of responses received by the IASB on the extractive activities project into IFRS 6 (Cortese \& Irvine, 2010). Secondly, IFRS 6 should include additional disclosure of the most significant asset of junior exploration companies, namely proved and probable mineral reserves. The above recommendations will improve the comparability, verifiability, timeliness and understandability of financial statements of junior exploration companies. 


\section{LIST OF REFERENCES}

Bryant, L. (2003). Relative value relevance of the successful efforts and full cost accounting methods in the oil and gas industry. Review of accounting studies, 8(1), pp. 5-28.

Cartwright, M.R. (1991). Accounting for mineral reserves. [0nline] Available: http://www.minval.com/mnrlacct_mineral.html. (Accessed 2 April 2013).

Cengage Learning. (2011). Additional online chapter on industry-specific IFRS: IFRS 6: Exploration for and evaluation of mineral resources. [Online] Available:

http://www.cengage.co.uk/abj4/students/ABJ4e\%20Additional\%200nline\%20Chapter.pdf. (Accessed 2 April 2013).

Chung, S. \& Narasimhan, R. (2006). Implications of International Financial Reporting Standard No. 6 for the Extractive Industry Companies in the United States. Oil, Gas \& Energy Quarterly, 55(2), pp. $283-292$.

Cortese, C. \& Irvine, H. (2010). Investigating international accounting standard setting: The black box of IFRS 6. Research in Accounting Regulations, 22(2), pp. 87-95.

Cortese, C. \& Irvine, H. \& Kaidonis, M. (2009). Extractive industries accounting and economic consequences: past, present and future. Accounting Forum, 33(1), pp. 27-37.

Czaja, R. \& Blair, J. (2005). Designing surveys: a guide to decisions and procedures, $2^{\text {nd }}$ edition. Thousand Oaks, CA: Pine Forge Press.

Epstein, B.J. \& Jermakowicz, E.K. (2009). Wiley IFRS 2009. Hoboken, New Jersey: John Wiley \& Sons, Inc. Gerhardy, P.G. (1999). Accounting for pre-production costs: Extracting consensus. Australian Accounting Review, 9(2), pp. 51-62.

International Accounting Standards Board (IASB). (2010). Discussion paper extractive activities. London: IASB

International Financial Reporting Standard (IFRS) Foundation. (2010). About extractive activities. [Online] Available:

http://www.ifrs.org/Current+Projects/IASB+Projects/Extractive+Activities/More+on+extractive+acti vities.htm. (Accessed 2 April 2013).

International Accounting Standards Board (IASB). (2013). A guide through International Financial Reporting Standards as issued at 1 July 2013. London: IFRS Foundation.

Kolb, B. (2008). Marketing research: a practical approach. London: SAGE.

KPMG. (2005). First impressions: IFRS 6 exploration for and evaluation of mineral resources. [0nline] Available:

http://www.kpmg.com/Ca/en/IssuesAndInsights/ArticlesPublications/Documents/IFRS/Firstimpressions-IFRS-6.pdf. (Accessed 2 April 2013).

KPMG. (2009). The application of IFRS: Mining. [Online] Available: http://www.kpmg.com/Global/en/IssuesAndInsights/ArticlesPublications/ILine-of-Businesspublications/Documents/IFRS-application-mining-Sep-2009.pdf. (Accessed 2 April 2013).

Leedy, P.D. (1988). Practical research: planning and design, $4^{\text {th }}$ edition. New York: Macmillan.

Lilien, S. \& Pastena, V. (1982). Determinants of intramethod choice in the oil and gas industry. Journal of Accounting and Economics, 4(3), pp. 145-170. 


\section{Sturdy \& Cronjé}

Luther, R. (1996). The development of accounting regulation in the extractive industries: An international review. The International Journal of Accounting, 31(1), pp. 67-93.

Malmquist, D.H. (1989). Efficient contracting and the choice of accounting method in the oil and gas industry. Journal of Accounting and Economics, 12(1-3), pp. 173-205.

Nichols, L.M. (2005). A new international standard: exploration for and evaluation of mineral resources. Oil, Gas \& Energy Quarterly, 54(2), pp. 267-272.

PricewaterhouseCoopers (PWC). (1999). Financial Reporting in the Mining Industry for the $21^{\text {st }}$ Century. [s.I]: PricewaterhouseCoopers.

PricewaterhouseCoopers (PWC). (2007). Financial reporting in the mining industry. [Online] Available: http://www.pwc.com/en_GX/gx/energy-utilities-mining/pdf/ifrs-mining.pdf. (Accessed 2 April 2013).

Republic of South Africa. (2002). Mineral and Petroleum Resources Development Act 28 of 2002. Pretoria: Government Printer.

Schonlau, M., Fricker, R.D. \& Elliott, M.N. (2002). Conducting research surveys via e-mail and the web. Santa Monica, CA: RAND

The South African Mineral Codes (SAMCODE). (2008). The South African code for the reporting of mineral asset valuation (SAMVAL code). Johannesburg: SAMCODE

Venter, $\varepsilon$. (2003). Pre-extraction costs in the mining industry. Accountancy SA, 22(45), pp. 2-3, 5. 